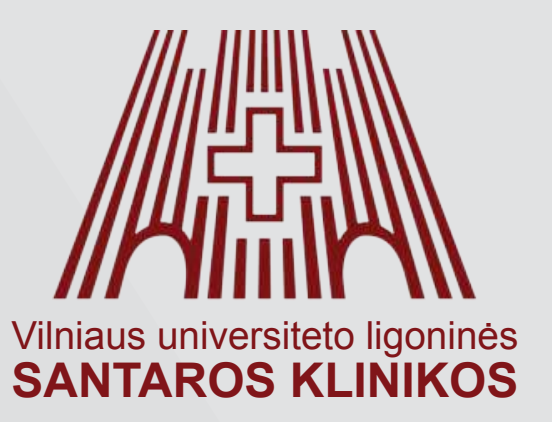

\title{
ASSESSING THE DYNAMICS OF ANXIETY AND DEPRESSION IN PATIENTS WITH LOW BACK PAIN DURING REHABILITATION
}

\author{
leva Kerzaitė, leva Jasiulionienė, Ramunè Lukštaitė, Gedvilè Paškauskaitė \\ Vilnius University Hospital Santaros Klinikos Rehabilitation, Physical and Sports Medicine Centre - Vilnius, Lithuania
}

\section{INTRODUCTION}

Psychological help plays an important role in accelerating recovery, returning to work and improving the quality of life. Patients with low back pain, in particular, feel higher levels of tension, psychological distress and lower satisfaction with life, related to restricted ability to move as well as experience of chronic pain.

\section{PURPOSE:}

Assess the dynamics of psychoemotional state of out-patients with chronic low back pain in rehabilitation.

\section{METHOD:}

During the assessment of the psychological condition, anxiety and depression tests were performed at the beginning and at the end of out-patients in rehabilitation.

The anxiety and depression were evaluated by Hospital Anxiety and Depression Scale (HADS) Zigmond A.S., Snaith R.P.

Fig. 1. Comparison of anxiety between gender in rehabilitation beginning and the end

\section{Anxiety}

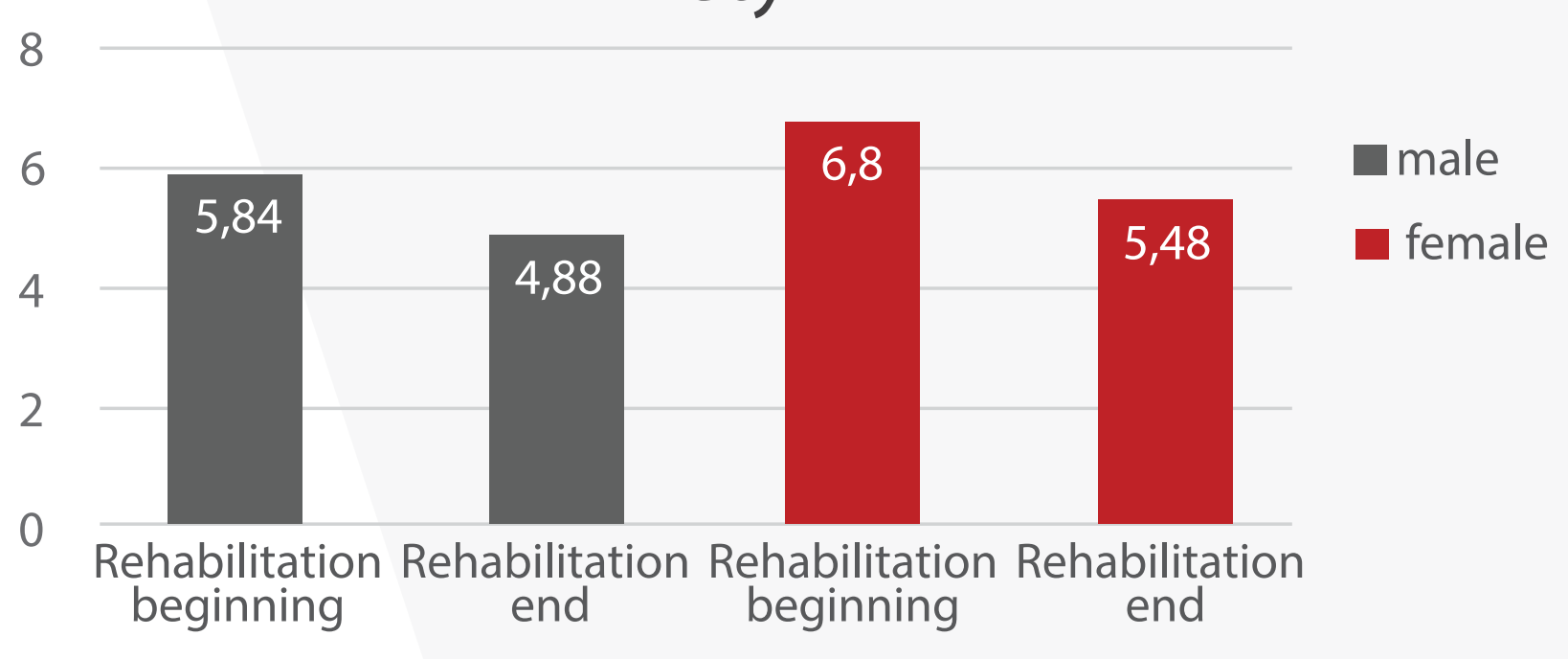

Fig. 2. Comparison of depression between gender in rehabilitation beginning and the end

\section{Depression}

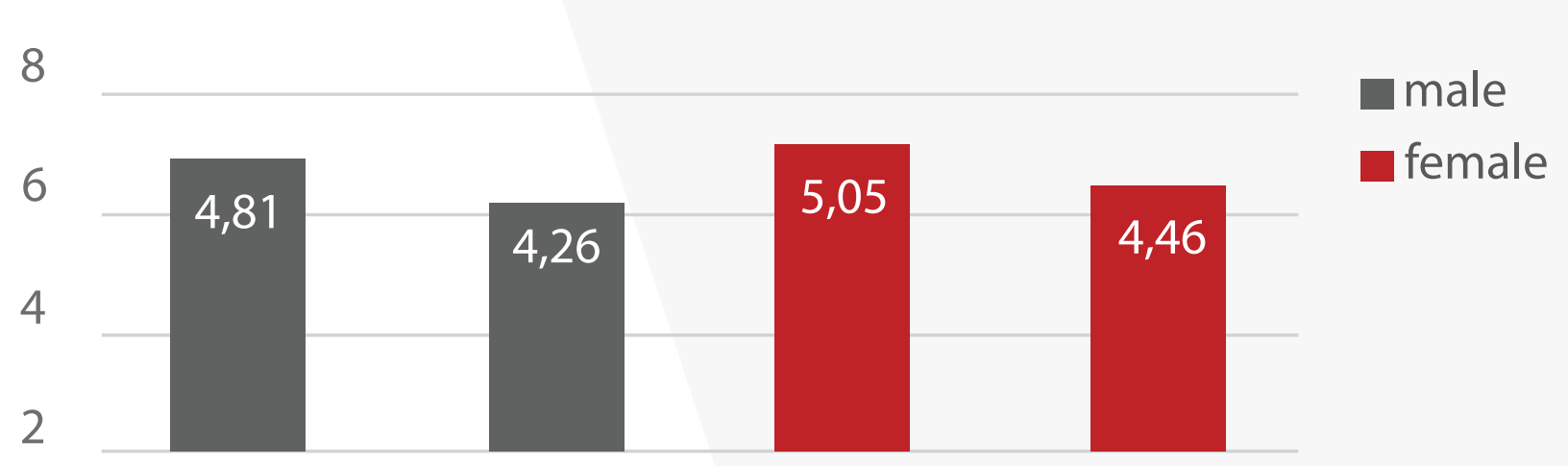

0 Rehabilitation Rehabilitation Rehabilitation Rehabilitation beginning end beginning end

\section{RESULTS:}

Study was conducted to evaluate the dynamics of psycho-emotional state of out-patients with chronic low back pain. Data being gathered in three-year period $2014-2017$. HAD scale was completed by 325 patients ( $21 \%$ male and 79 $\%$ female), average age of patients - 52,84 years. Patients received two consultations and seven relaxations sessions. Female patients showed higher anxiety as well as higher depression scores than male patients at the beginning of the rehabilitation process. Both groups got lower anxiety and depression scores during the final assessment of psychoemotional state. Female patients showed higher im provement in their anxiety scores than male group, while decrease in depression scores was slightly higher in male group.

Higher scores of the anxiety at the beginning as well as greater decrease in anxiety scores during the process of the rehabilitation registered in female participants might be related to their proneness to ruminate more when faced with life stressos, which is revealed by other studies $(1,2)$. Also, other studies show, when faced with stressful situations, men engage more in active, problem - focused coping strategies, in comparison with woman. This tendency might be related with lower anxiety scores in men group during the first evaluation. Depression rates at the beginning as well as decrease in depression scores during the rehabilitation process in both groups were similar.

\section{CONCLUSIONS:}

Re-evaluated psychoemotional state showed tendency to return to balance. The anxiety and depression scores got lower. The psychological counseling and self-regulation skills training during the rehabilitation relates to lower anxiety and depression estimates in both sexes by the end of the rehabilitation.

\section{REFERENCES:}

1. Remes et al. 2016. A systematic review of reviews on the prevalence of anxiety disorders in adult populations. Brain and behavior, 6(7), 1-33. 2. Clarke, D. M. \& Currie, K.C., 2009. Depression, anxiety and their relationship with chronic diseases: a review of the epidemiology, risk and treatment evidence. Med. J. Aust., 6, 54-60. 